\title{
Numerical simulations of the ISO $13785-2$ façade fire tests
}

\author{
Simo Hostikka and Gleb Bytskov \\ Aalto University, Espoo, Finland
}

\begin{abstract}
In this work we created a numerical model of the ISO 13785-2 test setup for testing the fire behaviour of building façade systems, and used the model to simulate the thermal environment on the façade. The model, created using Fire Dynamics Simulator software, was first validated using the experimental data by Yoshioka et al. (2012). Next, the sensitivity of the façade heat fluxes on the geometrical and model parameters was studied, revealing for instance that the size of the combustion chamber window will influence the thermal exposure high above the window. Finally, the model was used to estimate the thickness of non-combustible insulation layer that is needed to protect combustible materials from melting or decomposition.
\end{abstract}

\section{INTRODUCTION}

The development of test standards and fire safety classification basis for building façade products is currently an active topic of research and standardization activities in Europe and globally. The development of such standards requires investigation of the test characteristics, sensitivities of the produced fire exposure to the geometrical and environmental parameters, and the suitability of the test for the range of intended products. While the full-scale tests with alternative details cannot be avoided, many of the phenomena can be studied using Computational Fluid Dynamics simulations.

The goal of this work was to prepare a validated model for the ISO 13785-2 test setup and then use the model to investigate the sensitivity of the fire exposure at the façade to the physical and numerical parameters. An additional objective was to determine is the model can be used to determine geometrical and material requirements for the protection of combustible insulation materials. This research did not explore the hazards related to real fires, such as the fire spreading to the apartments above the fire or to adjacent buildings.

\section{METHODS}

\subsection{ISO 13785-2 standard test}

ISO 13785-2 is a relatively recent test standard for large-scale testing of building facade materials and products [1]. The test facility consists of a combustion chamber, facade specimen with side wall, opening and measurement devices. The combustion chamber has volume in range $20-100 \mathrm{~m}^{3}$, and it has a $2 \mathrm{~m}$ wide by $1.2 \mathrm{~m}$ high opening. The façade wall extends up to $4 \mathrm{~m}$ above the top edge of window, to the

This is an Open Access article distributed under the terms of the Creative Commons Attribution License 2.0, which permits unrestricted use, distribution, and reproduction in any medium, provided the original work is properly cited. 


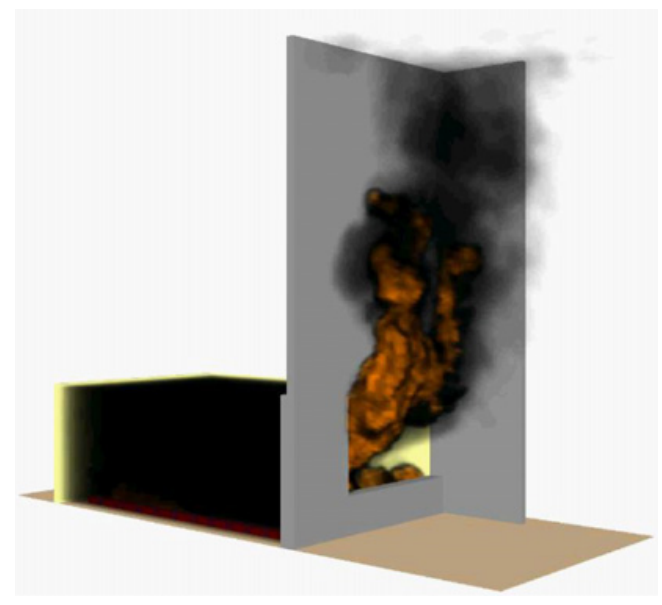

Figure 1. FDS model of the ISO 13785-2 test.

total height of $5.7 \mathrm{~m}$. The vertical side wall (wing) is $1.2 \mathrm{~m}$ wide with same height as the main façade specimen. Figure 1 shows the FDS model of the test setup with flames emerging from the combustion chamber to the façade.

According to ISO 13785-2 standard, any fuel can be used to produce a window flame which exposes the test specimen to heat flux of $55 \pm 5 \mathrm{~kW} / \mathrm{m}^{2}$ at a height $0.5 \mathrm{~m}$ above the opening, and $35 \pm 5 \mathrm{~kW} / \mathrm{m}^{2}$ at a height of $1.5 \mathrm{~m}$ above the opening. It is not necessary to perform ISO 13785-2 test with maximum heat release rate, if the exposure level on façade wall can be achieved with lower HRR. Annex A of the standard suggest that propane gas with $95 \%$ purity can be used for testing. Propane burner consists of perforated steel pipes, positioned uniformly in the room. Fuel flow rate reaches its maximum 5 minutes from the test start and decays to zero between 20 and $25 \mathrm{~min}$.

Heat fluxes are measured at $3.5 \mathrm{~m}$ above the top of the window, and thermocouples are installed at the top of the test specimen and at the top of the window opening. Evaluation or performance criteria are not included in the standard.

\subsection{Numerical}

The façade fire tests were modelled and simulated using Fire Dynamics Simulator (FDS), version 6.1 [2]. The current simulations were made with the modelling options that are commonly used in Fire Safety Engineering (FSE) applications, assuming, e.g., simple chemistry for combustion reactions and grey radiation. Wall-functions and empirical heat transfer coefficients were used for the wall stress and heat flux, respectively. Post-processing of the simulation results was performed with the Smokeview program and Matlab-routines.

In the context of compartment fire simulation, the quality of the computational mesh is commonly assessed using the non-dimensional $D^{*} / \delta x$ ratio, where $\delta x$ is the size of the grid cells and $D^{*}$ is a characteristic fire diameter

$$
D^{*}=\left(\frac{\dot{Q}}{\rho_{\infty} c_{p} T_{\infty} \sqrt{g}}\right)^{2 / 5}
$$

where $Q$ is the HRR, and $\rho_{\infty}, c_{p}, T_{\infty}$ and $g$ are the ambient density, specific heat, temperature and gravitation acceleration, respectively. Values of 10 or more for the $D^{*} / \delta x$ are required to obtain reliable predictions of the radiative heat flux [3]. Substituting the lowest considered value of HRR (25\% of the nominal value $5600 \mathrm{~kW}$ ) to Eq. (1) indicates that the cell size should be order of $10 \mathrm{~cm}$. 
The model included the chamber, façade and $3.0 \mathrm{~m}$ of empty space in front of the façade. The vertical and top boundaries of the external space were defined as open pressure boundaries. The burners were modelled as rectangular surfaces of propane inflow. The $10 \mathrm{~cm}$ cell size did not enable us to simulate the flows and heat transfer in the gap between the façade and chamber, but the role of this simplification is expected to be minor.

\subsection{Validation experiments}

For the validation of the FDS model, we used the experimental data measured at the Tokyo University of Science (TUS) in a research project with partners from the Japanese National Institute of Land and Infrastructure Management, and Building Research Institute. The experiments have been summarized by Yoshioka et al. [4]. They measured nearby gas temperatures and total heat fluxes to a non-combustible façade specimen at different heat release rates and in different ventilation configurations.

The test apparatus consisted of the combustion chamber and the façade test specimen, dimensioned according to the standard. Combustion chamber walls and ceiling were made from (starting from outside) $6 \mathrm{~mm}$ steel plates and $50 \mathrm{~mm}$ ceramic fibre boards. Floor of combustion chamber was constructed of (starting from outside) $6 \mathrm{~mm}$ steel plate, $50 \mathrm{~mm}$ ceramic fibre board and $25 \mathrm{~mm}$ ceramic fibre blankets. The dimensions of the combustion chamber were $4.0 \times 4.0 \times 1.7$ meters. (Note that the chamber size, as well as some other features were reported incorrectly in [4].) The façade specimen consisted of a main wall with dimensions $3 \times 5.7 \mathrm{~m}$ (width and height) and a $1.2 \mathrm{~m}$ wide side wall with the same height. The façade wall specimens were constructed of $25 \mathrm{~mm}$ ceramic fibre blankets on the surface exposed to fire and $25 \mathrm{~mm}$ calcium silicate boards connected to the steel frame.

There were three series of tests with propane gas used as fire source. Each series of tests was done with some modifications to the standard ISO test. According to the ISO 13785-2, it is possible to make vents on the opposite side of the combustion chamber in order to enhance the buoyancy-driven ventilation. In the TUS tests, the combustion chamber was equipped with four of these openings. First group of tests, marked with I-letter, was done with regular façade window and with one rear side opening opened. The second group of tests, marked with (1)-sign, were performed with all four vents opened. In the last group of tests, marked with (2)-sign, all of supplemental openings were closed, and the façade window dimensions were modified to investigate the effect of the flame characteristics. In each series, two or three consecutive tests were performed with different propane flow rates and, consequently, heat release rates. The tests conditions are summarized in Table 1 . The tests were carried out one after another, so that there was a $10 \mathrm{~min}$ cooling period between the 5 min tests.

The simulated HRR and mass burning rate histories are shown in Fig. 2. Spatial resolution of $10 \mathrm{~cm}$ was used. An additional empty space was added to the back of the combustion chamber for accurate computation of the flows through the rear vents. Initial temperature was set to $40^{\circ} \mathrm{C}$ based on the measurement data, although the vertical stratification of the test hall was not taken into account.

The instrumentation of the experiments was more comprehensive than what is required by the ISO standard. Thermocouple and heat flux gauge positions on the façade are shown in Fig. 3. Thermocouples were simulated using the FDS's built-in thermocouple models, with bead diameters $3.2 \mathrm{~mm}$ (on the façade) and $1.6 \mathrm{~mm}$ inside the chamber. For heat flux, a numerical model for the water-cooled heat flux gauges was used.

\section{RESULTS AND DISCUSSION}

\subsection{Validation results}

Performing a rigorous model validation using experimental data is a long and laborious exercise. Despite the relative quick throughput of the simulation process, it takes several iterations to confirm experimental 
Table 1. Validation tests from [4].

\begin{tabular}{|c|c|c|c|c|c|c|c|c|}
\hline \multirow{2}{*}{ Case } & \multirow{2}{*}{$\begin{array}{c}\text { Heating } \\
\text { Load }\end{array}$} & \multirow{2}{*}{$\begin{array}{c}\text { Test } \\
\text { duration }\end{array}$} & \multirow{2}{*}{$\begin{array}{c}\text { Gas } \\
\text { flow } \\
(\mathrm{m} 3 / \mathrm{h})\end{array}$} & \multirow{2}{*}{$\begin{array}{l}\text { HRR } \\
\text { (MW) }\end{array}$} & \multicolumn{3}{|c|}{ Opening } & \multirow{2}{*}{$\begin{array}{l}\text { Vents at rear of } \\
\text { chamber }\end{array}$} \\
\hline & & & & & $\mathrm{B}(\mathrm{m})$ & $\mathrm{H}(\mathrm{m})$ & $\mathrm{B} /(\mathrm{H} / 2)$ & \\
\hline $\mathrm{I}-1$ & $\begin{array}{l}1 / 2 \text { of } \\
\text { ISO }\end{array}$ & $5 \mathrm{~min}$ & 225 & 2.8 & 2 & 1.2 & 3.3 & $\begin{array}{l}\text { 3: Closed } \\
\text { 1: Open }\end{array}$ \\
\hline $\mathrm{I}-2$ & $\begin{array}{l}3 / 4 \text { of } \\
\text { ISO }\end{array}$ & $5 \mathrm{~min}$ & 337.5 & 4.2 & 2 & 1.2 & 3.3 & $\begin{array}{l}\text { 3: Closed } \\
\text { 1: Open }\end{array}$ \\
\hline (1) -1 & $\begin{array}{l}1 / 4 \text { of } \\
\text { ISO }\end{array}$ & $5 \mathrm{~min}$ & 112.5 & 1.4 & 2 & 1.2 & 3.3 & All (4) open \\
\hline (1) -2 & $\begin{array}{l}1 / 2 \text { of } \\
\text { ISO }\end{array}$ & $5 \mathrm{~min}$ & 225 & 2.8 & 2 & 1.2 & 3.3 & All (4) open \\
\hline (1) -3 & $\begin{array}{l}3 / 4 \text { of } \\
\text { ISO }\end{array}$ & $5 \mathrm{~min}$ & 337.5 & 4.2 & 2 & 1.2 & 3.3 & $\begin{array}{l}\text { Former: All open } \\
\text { Latter: } 2 \text { closed }\end{array}$ \\
\hline (2) -1 & $\begin{array}{c}1 / 8 \text { of } \\
\text { ISO }\end{array}$ & $5 \min$ & 56.25 & 0.7 & 2 & 0.2 & 20 & All (4) closed \\
\hline (2) -2 & $\begin{array}{l}1 / 4 \text { of } \\
\text { ISO }\end{array}$ & $5 \mathrm{~min}$ & 112.5 & 1.4 & 2 & 0.5 & 8 & All (4) closed \\
\hline (2) -3 & $\begin{array}{l}1 / 2 \text { of } \\
\text { ISO }\end{array}$ & $5 \mathrm{~min}$ & 225 & 2.8 & 2 & 1 & 4 & All (4) closed \\
\hline
\end{tabular}

details, to observe and fix the mistakes and errors in the publications presenting the experimental results, and to estimate the unknown input parameters. The results presented below represent a work-in-progress in this respect.

The simulation results were used to quantify the uncertainty of three FDS output quantities: gas temperature within the combustion chamber, gas temperature at the façade, and surface heat flux at the façade. Figure 4 shows simulated chamber temperatures in tests I-1 and I-2 for "Pole A", a vertical tree of thermocouples in the corner of the chamber that was near the front wall on the left. As we can see, the model uncertainty is of the same order or even less than the current FDS validation database estimate for the hot gas layer temperature in naturally ventilated fires (Bias $=1.07$ and relative standard deviation of 7\%). Unfortunately, much worse results were obtained for some other tests of the TUS series. This can be seen in Fig. 5 that shows the scatterplot of the predicted vs. measured peak temperatures for all eight tests and $2 \times 5$ thermocouples. In average, the simulations overestimate the temperatures by $16 \%$ and the relative standard deviation is $26 \%$. The current uncertainty metric is not fully comparable to that of FDS Validation Guide because in there, the comparison is made using an average of several thermocouples for each test, thus reducing the influence of local fluctuations and details.

The comparisons of the façade gas temperatures were made at different heights above the window, ranging from $0.05 \mathrm{~m}$ to $4.0 \mathrm{~m}$. For the heat flux, the comparisons were made between 0.9 and $2.0 \mathrm{~m}$ above the window. Figure 6 shows a comparison of the gas temperatures and heat fluxes at three different vertical lines ( $\mathrm{a}$ on the left, $\mathrm{b}$ in the middle, $\mathrm{c}$ on the right) for Test I-2. These results are among the best predictions and do not represent a "typical" behaviour. Different colours of the curves correspond to different heights. Solid lines are experimental data and dashed lines are FDS results. Highest temperatures and heat fluxes are, in this test, obtained in the line middle of the window (line b). Combining the results for all tests and all thermocouples/heat flux gauges provides us with the following uncertainty metric: The temporal peak values of the plume temperatures in different locations are, in 


\section{Test series I}

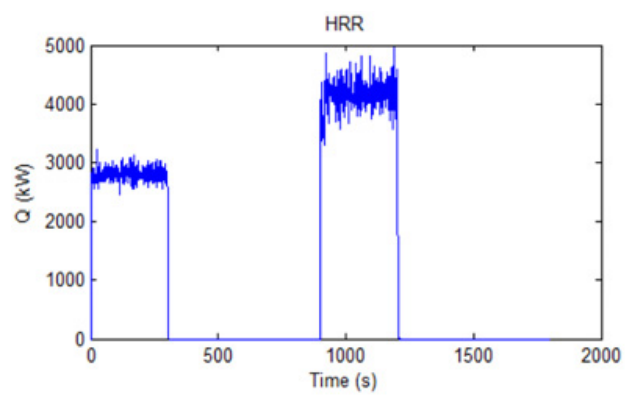

Test series (1)

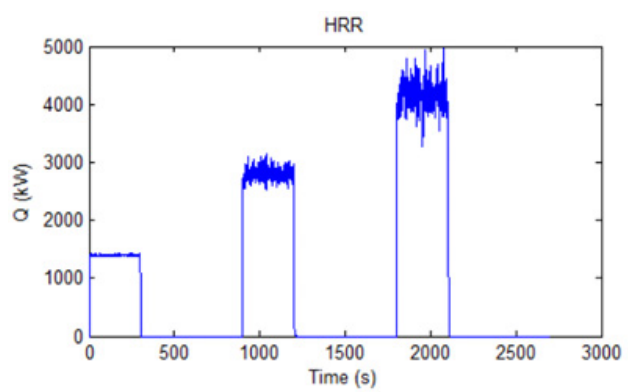

Test series (2)

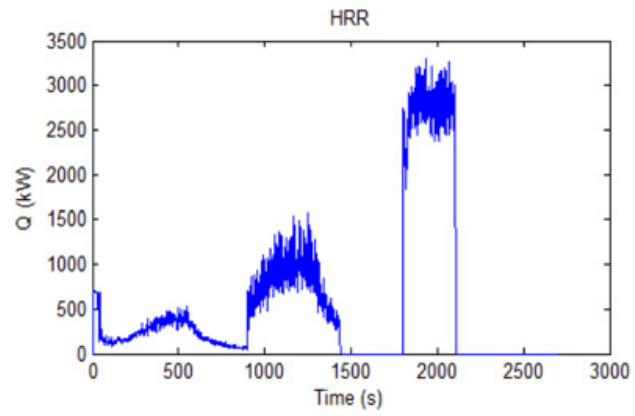

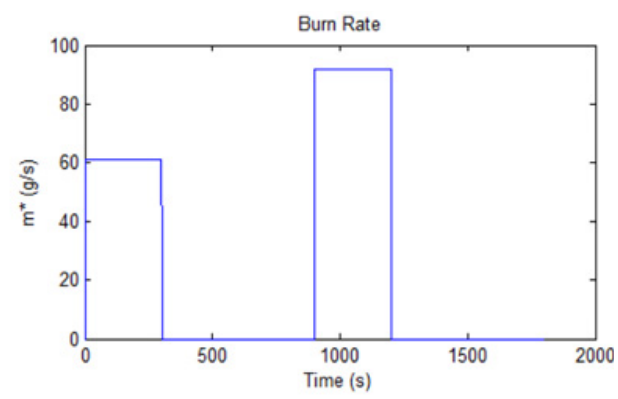
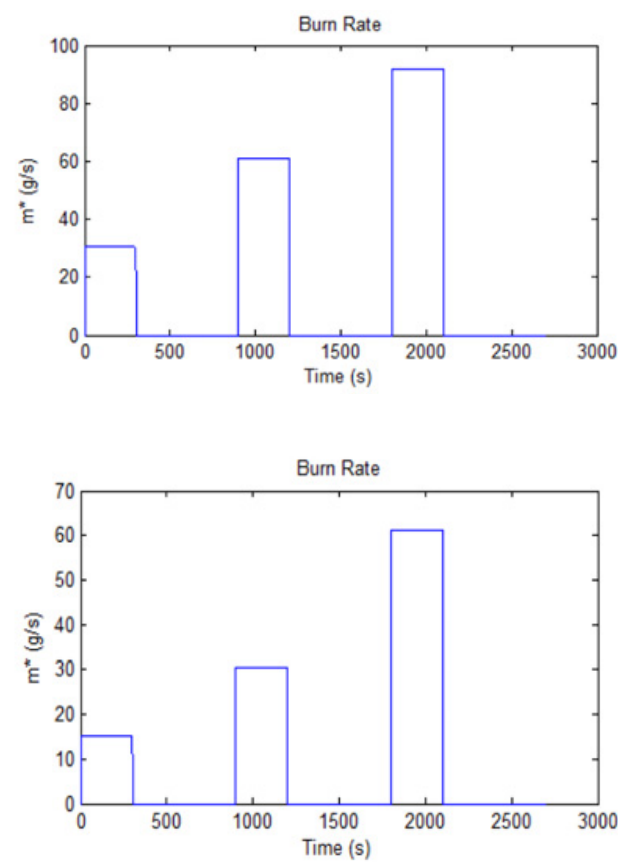

Figure 2. HRR and burning rate histories of the validation simulations.

average, underestimated by $18 \%$ and the heat fluxes overestimated by $14 \%$. These bias factors are not significantly greater than those determined from the current validation database. The relative standard deviations are, however, much greater: $56 \%$ for temperature rise and $66 \%$ for the heat flux. More detailed analysis is needed to understand what is behind these uncertainties. It is clear that some of the simulation results are even qualitatively different from the corresponding measurement. For instance, in some tests, the heat fluxes on one of the three lines ( $\mathrm{a}, \mathrm{b}$ and $\mathrm{c}$ ) were overestimated while others were underestimated. The asymmetric geometry of the tests appears to cause difficulties as the horizontal location of the window plume has a strong influence on the observed temperatures and heat fluxes. In symmetrical geometries, both experiment and simulation would be predictable as the peak temperatures would be observed on the symmetry axis of the setup. Here, a slight difference in the actual plume position can cause a significant difference between the experiment and simulation.

In addition to the plume location issues, the exact characteristics and operational procedures of the gas burners was not known for the simulation boundary condition. Also, the hydrodynamic conditions 


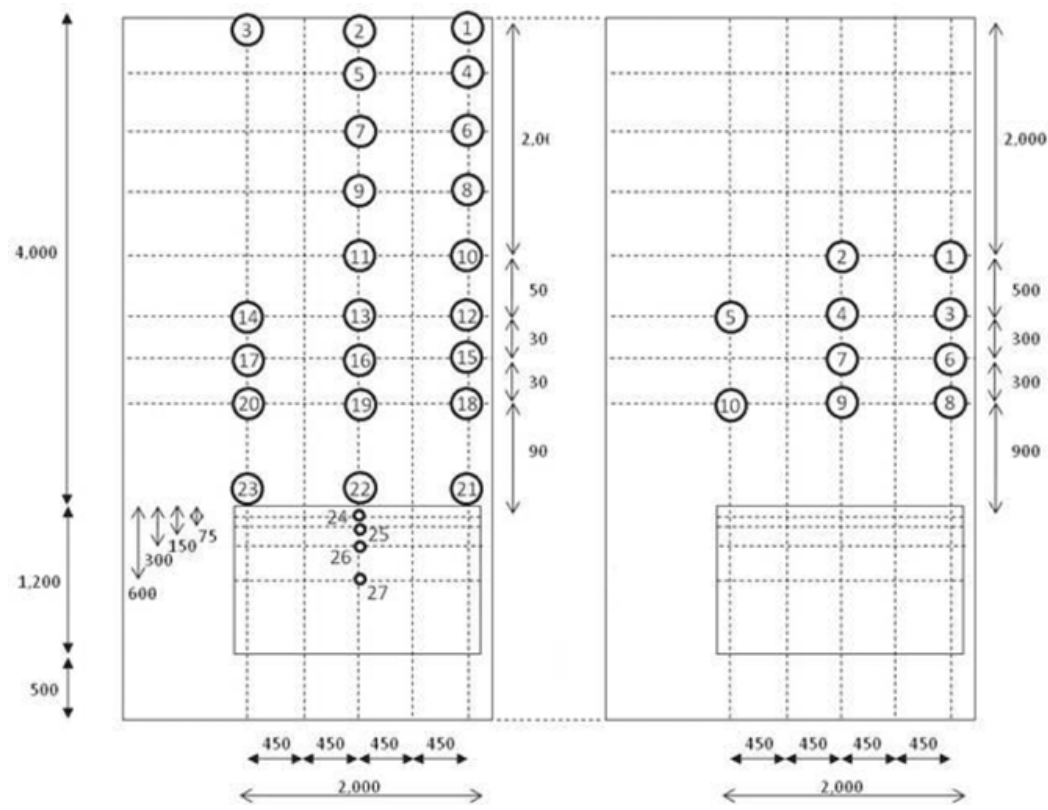

Figure 3. Facade instrumentation in the TUS tests [4]: thermocouples (left) and heat flux gauges (right).
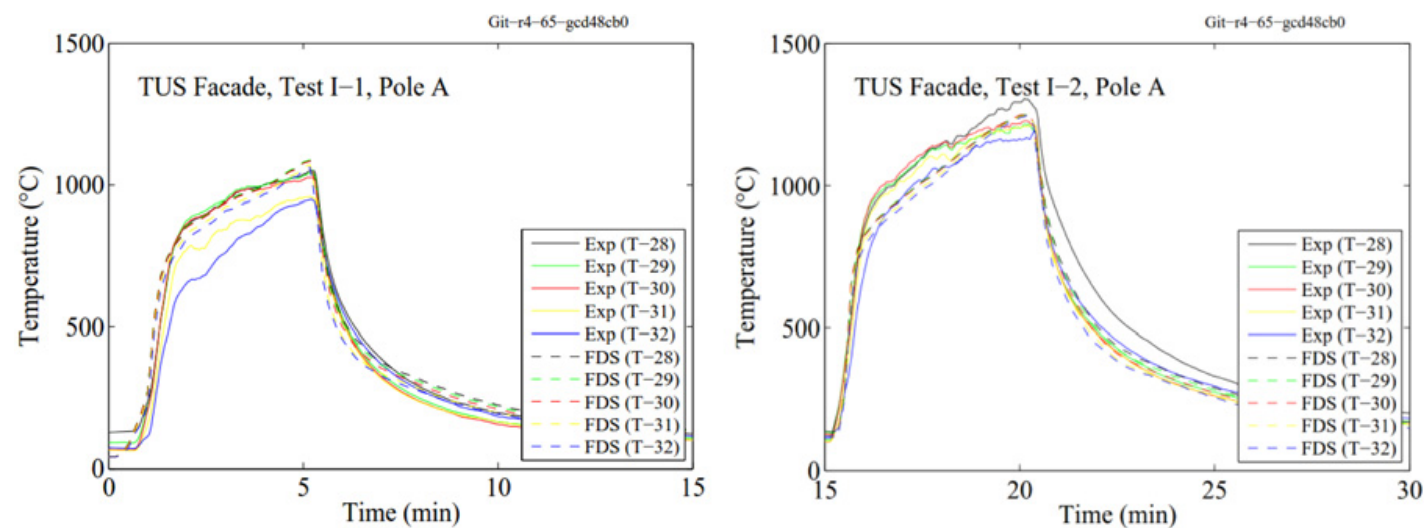

Figure 4. Combustion chamber temperatures in tests I-1 and I-2.

in the tests with two-sided ventilation included some uncertainties which may be reflected in the temperatures of combustion chamber internal temperatures.

\subsection{Sensitivity study}

The sensitivity of the ISO 13785-2 simulation predictions on the physical and numerical parameters was next investigated. Simulations were made with the following characteristics:

- Maximum heat flux corresponds to fuel supply flowrate of $120 \mathrm{~g} / \mathrm{s}$.

- Fuel flowrate increased linearly from zero to maximum in first 5 minutes of simulation.

- Simulation was extended for two minutes with maximum flowrate. 


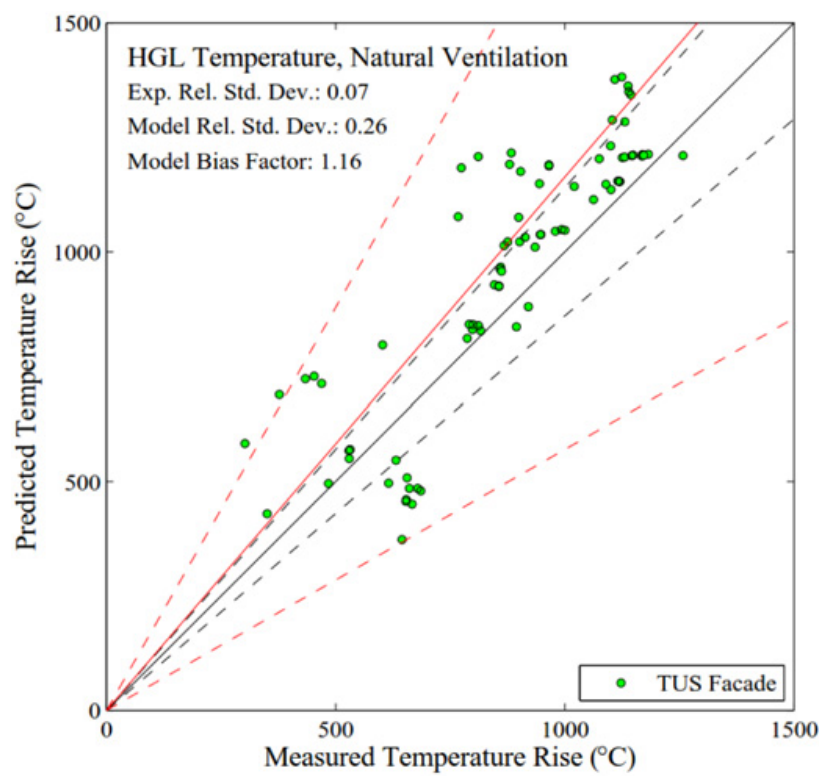

Figure 5. Uncertainty statistics for all the combustion chamber gas temperatures of the TUS series.

The results are summarized by presenting the maximum surface heat fluxes at two heights above the window for different alternations of test setup and the radiative fraction (Fig. 7). The geometrical features of the test setup were varied within the range allowed by the standards. The results show that both widening the combustion chamber and introducing additional ventilation to the back of the chamber will reduce the heat fluxes. These findings can help in the design of test sites, but they do not significantly affect the interpretation of the test results because the HRR of the fire would in any case be calibrated to produce the requested heat flux $\left(55 \pm 5 \mathrm{~kW} / \mathrm{m}^{2}\right)$ on the façade.

Low left hand - side plot of Fig. 7 shows that the variations in the window size did not affect the heat flux at $0.6 \mathrm{~m}$ above the window, but at $3.6 \mathrm{~m}$ above the window, a larger window would cause lower heat fluxes. This is an important finding because the overall exposure to the façade seems to be dependent on the window sizing while the flux at the calibration height is not.

Finally, the effect of the combustion reaction radiative fraction was investigated. The results shows that increasing radiative fraction will also increase the heat flux. This is due to the fact that the test typically shows a large flame emerging out of the window, and thus the heat flux is mainly by radiation. Similar result was obtained by increasing the soot yield of the combustion reaction. The quality of the fuel can therefore influence the heat fluxes, and must be kept in mind in the calibration. In reality, however, the radiative behavior can be different inside and outside the chamber if the fire is in the ventilation controlled regime.

The sensitivity of the heat fluxes on the numerical resolutions of the simulation was also investigated. Reducing the spatial grid cell size from $10 \mathrm{~cm}$ to $5 \mathrm{~cm}$ increased the heat fluxes few percent. The angular resolution of the radiation solution, in turn, did not have a significant impact on the heat fluxes. Nor had the resolution of the solid-phase heat conduction solver.

\subsection{Application example}

The validated simulation model was used to investigate the thermal protection requirement for the insulation products that are based on synthetic polymers. The heat flux distribution on the whole façade 

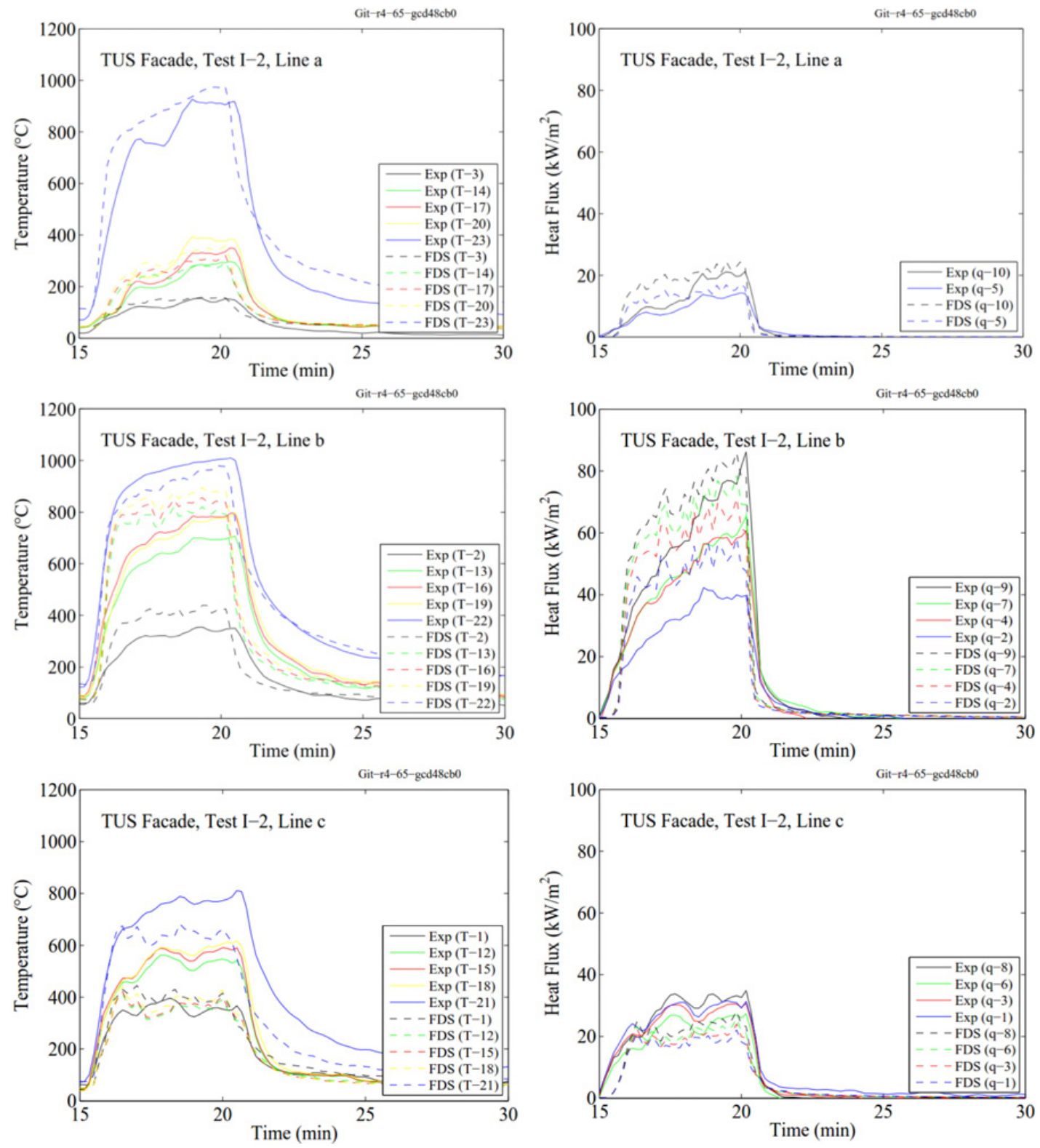

Figure 6. Façade gas temperatures (left column) and heat fluxes (right column) for Test I-2.

surface was first simulated over the time period required by the standard. An instantaneous distribution is shown in Fig. 8. The highest heat fluxes are observed just above the window's left part, and on the right-wing wall close to the window. Higher above the window, the plume bends towards the corner focusing the high-heat flux region.

Heat flux histories were saved from the region above the window, and used as a boundary condition for one-dimensional heat conduction solver. This procedure can be repeatedly used to investigate different materials or their combinations without the actual CFD simulation. By setting the thermal properties of the façade material to those of stone wool, we investigated the temperatures at different 
$2^{\text {nd }}$ International Seminar for Fire Safety of Facades, Lund (Sweden), 2016
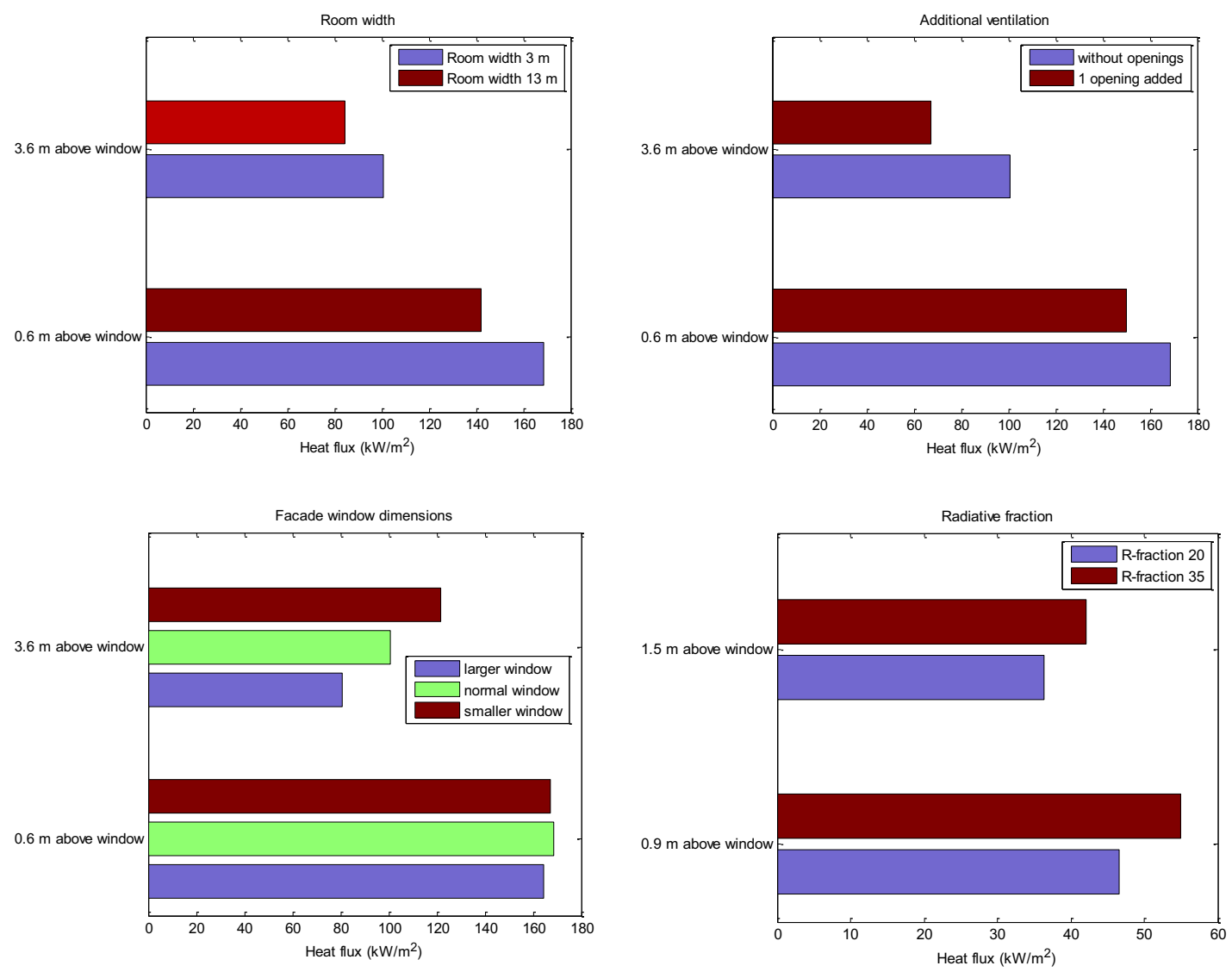

Figure 7. Sensitivity of the predicted heat fluxes on the geometrical alterations and radiative fraction.

Table 2. Required stone wool protection thickness to protect combustible insulation materials.

\begin{tabular}{|c|c|c|}
\hline \multirow{2}{*}{ EPS } & \multicolumn{2}{|c|}{ Required Stone wool thickness against } \\
& Melting $\left(200^{\circ} \mathrm{C}\right)$ & $70 \mathrm{~mm}$ \\
& Burning $\left(300^{\circ} \mathrm{C}\right)$ & $60 \mathrm{~mm}$ \\
\hline PIR & Slow degradation/burning $\left(100^{\circ} \mathrm{C}\right)$ & $90 \mathrm{~mm}$ \\
& Fast degradation/burning $\left(300^{\circ} \mathrm{C}\right)$ & $60 \mathrm{~mm}$ \\
\hline
\end{tabular}

depths. Maximum (over time) temperatures behind $60 \mathrm{~mm}$ and $90 \mathrm{~mm}$ layers of stone wool are shown in Fig. 9. The peak temperatures at these depths are $277^{\circ} \mathrm{C}$ and $97^{\circ} \mathrm{C}$, respectively.

Using the simulations results, and assuming certain critical temperatures for the plastic insulation materials, we can estimate the thickness of stone wool that is needed to prevent the damage. The results are summarized in Table 2. The two materials are Expanded polystyrene (EPS) and Polyisocyanurate (PIR). The threshold temperatures were taken from analytical experiments of individual products, and therefore, the results cannot be generalized for other products using similar materials, as the critical temperatures can vary. We can see that $70 \mathrm{~mm}$ of stone wool is needed to prevent the melting of EPS. For PIR, about $60 \mathrm{~mm}$ of protective material is needed to prevent the main thermal degradation reaction at $300^{\circ} \mathrm{C}$, but as much as $90 \mathrm{~mm}$ is required to prevent the slower degradation reaction around $100^{\circ} \mathrm{C}$. 

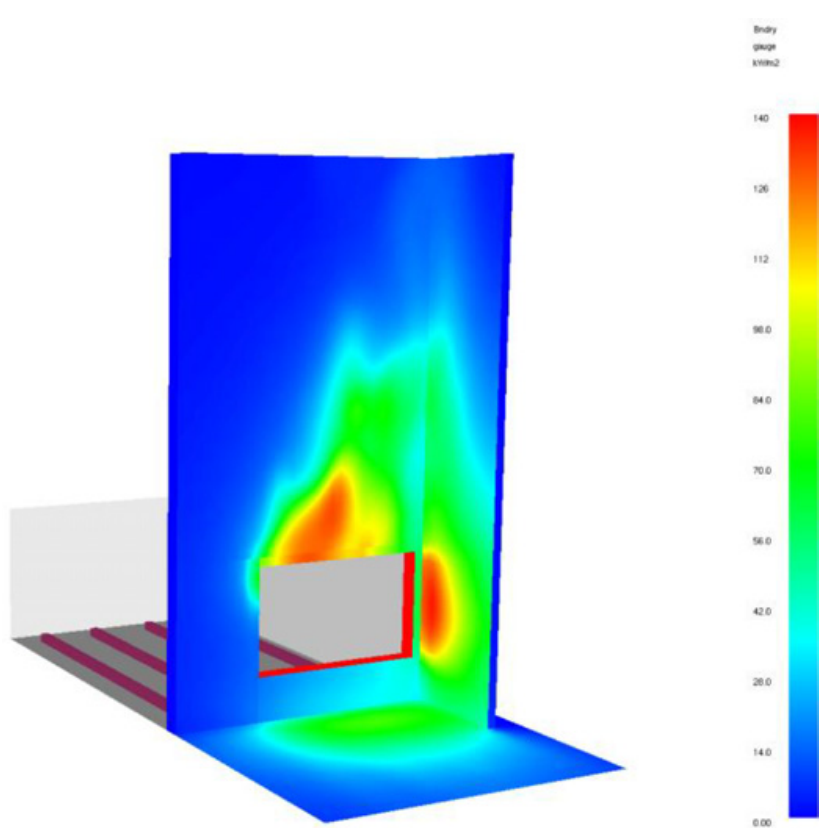

Figure 8. Instantaneous heat flux distribution on the façade.
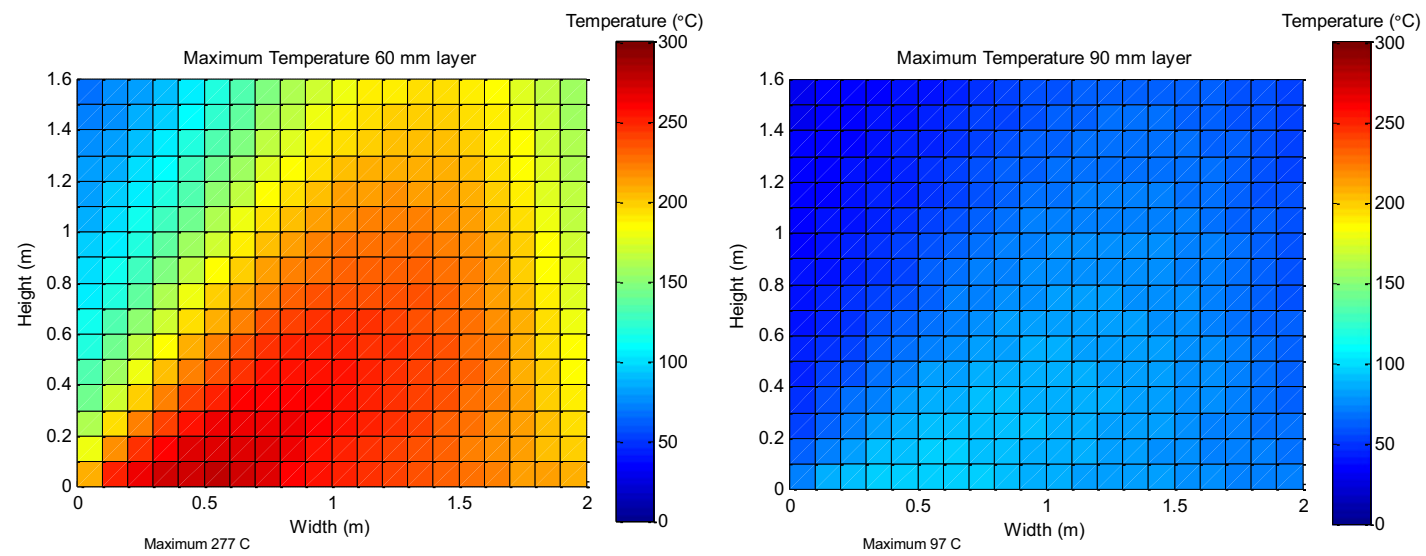

Figure 9. Maximim temperatures behind $60 \mathrm{~mm}$ (left) and $90 \mathrm{~mm}$ (right) layers of stone wool.

\section{CONCLUSIONS}

Numerical simulations of the ISO 13785-2 façade fire test were used to investigate the sensitivity of the thermal exposure on the façade to the geometrical and model-related parameters. The simulation model was first validated against experimental data. In some tests, the model uncertainty was very low, but the overall standard deviation in the simulation data was higher than the current state of the model validation database. In average, the façade temperatures were underestimated by $18 \%$ and the heat fluxes overestimated by $14 \%$. Further investigation of the simulation setup and determination of the partially unknown experimental details continues. The current findings show, already, that the experiments used 
for CFD validation should be designed symmetric to avoid large local errors in thermal predictions due to the otherwise insignificant uncertainties in fire plume position.

The sensitivity study indicated that the heat fluxes in the upper part of the façade are affected by the windows size although the values in the calibration region are not. In addition, the sootiness and high radiative fraction of the fuel were found to increase the façade heat fluxes.

The model was then used to estimate the thickness of non-combustible insulation layer that is needed to protect combustible materials from melting or decomposition. In addition, a procedure was developed for the calculations of the material behaviour without repeated large-scale CFD simulations. Such a procedure can be efficiently applied in product and material R\&D.

\section{References}

[1] ISO 13785-2:2002. Reaction-to-fire tests for facades - Part 2: Large-scale test. International Organization for Standardization, 2002.

[2] McGrattan, K., McDermott, R., Floyd, J., Hostikka, S., Forney, G., \& Baum, H. "Computational fluid dynamics modelling of fire”. International Journal of Computational Fluid Dynamics, 1-12, 2012.

[3] Lin, C.H., Ferng, Y.M., \& Hsu, W.S., "Investigating the effect of computational grid sizes on the predicted characteristics of thermal radiation for a fire", Applied Thermal Engineering, 29(11-12), 2243-2250, 2009.

[4] Yoshioka, H., Ohmiya, Y., Noaki, M., \& Yoshida, M. "Large-scale Facade Fire Tests Conducted Based on ISO 13785-2 with Noncombustible Facade Specimens", Fire Science and Technology, 31, 1-22, 2012. 